Competition and Crowding-Out among Public, NonProfit and For-Profit Organizations: Evidence from Outpatient Substance Abuse Treatment

\author{
Andrew Cohen \\ Federal Reserve Board of Governors \\ Beth Freeborn \\ College of William and Mary \\ Brian McManus \\ Olin School of Business, Washington University
}

College of William and Mary

Department of Economics

Working Paper Number 52

May 2007 
COLLEGE OF WILLIAM AND MARY

DEPARTMENT OF ECONOMICS

WORKING PAPER \#52

May 2007

\title{
Competition and Crowding-Out among Public, Non-Profit and For-Profit Organizations: Evidence from Outpatient Substance Abuse Treatment
}

\begin{abstract}
U.S. markets for outpatient substance abuse treatment (OSAT) include clinics that are private for-profit, private non-profit, and public (i.e., government-run). We study the market structure of OSAT using recently-developed methods from the empirical industrial organization literature on equilibrium market structure in differentiated product markets. These methods allow us to describe OSAT clinics as heterogeneous in their objectives, their responses to exogenous market characteristics, and their responses to one another. We find that the presence of a public clinic in a market reduces the probability that a private clinic will also participate in the market, which is consistent with crowding-out between public and private provision of OSAT. Crowding out appears to be more prevalent in markets with larger white populations.
\end{abstract}

JEL Codes: C35, C72, H4, I1, L1, L3

Keywords: discrete games, multiple equilibria, structural estimation, healthcare markets, substance abuse treatment, crowding out

Andrew M. Cohen

Federal Reserve Board of

Governors

Washington, DC 20551

Andrew.M.Cohen@frb.gov
Beth Freeborn

Department of Economics

College of William and Mary

Williamsburg, VA 23187

bafree@wm.edu
Brian McManus

Olin School of Business

Washington University

Campus Box 1133

St Louis. MO 63130

mcmanus@wustl.edu 


\section{Introduction}

A significant share of U.S. public resources is dedicated to providing goods and services for which close substitutes may be obtained from the private sector. Examples include education, healthcare, and housing. Among both academics and policy makers there is extensive debate on the extent to which publicly provided goods can and should substitute for similar, privately provided goods. ${ }^{1}$ In many cases, both the government and private sector produce a positive amount of a good. While the presence of public providers may be viewed positively as part of a "social safety net," public provision may also have the negative consequence of crowding-out private producers of the same good. If a private organization is able to provide the good at lower cost or higher quality than the government, then there may be a welfare loss in the market. ${ }^{2}$ Questions regarding substitution and crowding out also extend to differences between private non-profit and for-profit organizations.

In this paper we estimate the relationship among public, private non-profit, and private for-profit provision of outpatient substance abuse treatment (OSAT). We focus on the decision of an OSAT clinic to be active within a market. We assume that organizations of each type (including public clinics) behave strategically in their responses to other clinics' participation choices. Because the decision to participate in a market is discrete and clinics are heterogeneous, we explicitly account for the possibility of multiple equilibria in the ownership of clinics which are active in a market. Our goal is to estimate the objective functions that govern activity by each type of organization, and in particular determine how the provision of OSAT by one type of clinic affects the objective functions (and actions) of the other clinics. ${ }^{3}$ Our modelling approach allows us to estimate the extent to which government provision of OSAT crowds out private provision, and how this effect depends on the for-profit status of the private clinic.

Previous research on the relationship among public, private non-profit, and private for-profit organizations has explicitly or implicitly relied on an assumption of a unique equilibrium in the actions of the organizations. When individual organizations make discrete (and interrelated)

\footnotetext{
${ }^{1}$ There exists a rich literature on the relationship between public health programs (e.g. Medicaid) and privately provided health insurance. For examples, see Cutler and Gruber (1996); Brown and Finkelstein (2006); ShoreSheppard, Buchmueller, and Jensen (2000); Rask (2000); and Lo Sasso and Buchmueller (2004). The relationship between private charitable contributions and public spending is studied by Kingma (1989), Andreoni (1993), and Gruber and Hungerman (2005). Blomquist and Christiansen (1999) review the literature on political economy explanations for the equilibrium presence of public provision.

${ }^{2}$ The welfare tradeoff of private provision would involve weighing consumers who would prefer the good if it were provided by the private sector against consumers who either prefer the publicly provided good or would be excluded from it without public provision.

${ }^{3}$ We interpret the objective of a for-profit clinic as profit maximization, while government and non-profit clinics maximize a payoff function that likely depends on other goals.
} 
decisions to be active in a market, however, these choices are often characterized by multiple equilibria in the identities and possibly the number of active organizations. This presents an interesting and difficult challenge for researchers and policy analysts. Econometric models which admit multiple equilibria may be considered "incomplete" (Tamer, 2003) or "logically inconsistent" (e.g. Maddala ch. 5, 1983). By explicitly accounting for this attribute of the model, however, we better estimate the degree to which a publicly provided good crowds out private provision, and how non-profit and for-profit private organizations affect each others' entry into markets.

Our modelling and estimation strategy builds on recently-developed techniques from the industrial organization (IO) literature. In their study of airline entry, Ciliberto and Tamer (2006) estimate an entry model in which more than one market outcome may be consistent with the model, yet the model does not impose an equilibrium selection mechanism to resolve the multiplicity. Related papers by Andrews, Berry, and Jia (2004) and Cohen and Manuszak (2005) use similar methods to estimate models of retailer and bank entry, respectively. Earlier empirical research on entry games typically include assumptions on the form of the game or the nature of the dependent variables in order to insure that the equilibrium of the game is always unique. ${ }^{4}$ Such restrictions are not appropriate for OSAT markets, which are complicated by likely differences in agents' objective functions and the policy relevance of whether public clinics crowd-out private clinics. If this occurs, a market may support more than one outcome, e.g., a market might have either one government clinic or one private clinic, but not one of both. Further, the stable ownership characteristics of OSAT clinics prevents a resolution of this multiplicity by allowing a clinic to adopt the ownership structure that maximizes its own payoffs. ${ }^{5}$ In accounting for multiple equilibria in the provision of a healthcare service, we also add to the general literature on competition in medical markets. ${ }^{6}$ While the industrial organization of healthcare is a large and growing area for study, we know of no other paper which consistently estimates the magnitude of substitution among public, non-profit,

\footnotetext{
${ }^{4}$ Prominent and early examples of this are Bresnahan and Reiss (1991) and Berry (1992), which both consider entry games with homogeneous goods. Mazzeo (2002) analyzes the effect of market structure on the performance of firms in a differentiated oligopoly market, but he avoids multiple equilibria by placing restrictions on the form of the entry game and making assumptions on payoffs.

${ }^{5}$ This is a critical difference between the present paper and Mazzeo (2002), in which potential motel owners' ability to choose quality levels eliminates the possibility of multiple equilibria.

${ }^{6}$ Gaynor and Vogt (2003) examine competition in the hospital industry with regard to the effect of ownership type and find not-for-profit hospitals have less elastic demand and lower marginal costs. Duggan (2000, 2002) offers empirical evidence that public, not-for-profit and for-profit firms respond differently to an exogenous change in financial incentives. Abraham, Gaynor and Vogt (2006) apply the Bresnahan and Reiss (1991) entry model to competition among hospitals, and find that competition gets tougher with the entry of the second firm but these effects are exhausted at the third firm. Chakravarty, Gaynor, Klepper and Vogt (2006) measure the effect of ownership structure on entry and exit in the hospital market and find that for-profit hospitals are more responsive than not-for profit firms to exogenous changes in demand.
} 
and for-profit healthcare providers through their decisions to be active in a market.

Our results indicate that strategic interactions among public, non-profit and for-profit clinics are an important determinant of OSAT provision. We estimate that the observed markets have a probability of multiple equilibria that is between $24.2 \%$ and $39.4 \% .^{7}$ We then use our model to perform a counterfactual experiment in which all government clinics exit their markets, and we find that private organizations respond by replacing between $90.3 \%$ and $92.7 \%$ of the missing public clinics. One perspective on this result is that public clinics crowd out private provision of OSAT. This result, however, does not apply equally to all markets. Treatment markets with relatively large minority populations are more likely to be served by public clinics than private clinics, and when public OSAT is removed from these markets the replacement by private facilities is not as strong. We perform additional counterfactuals that allow us to determine which markets are at risk for exclusion from any OSAT services. In these "marginal markets" we find that public clinics are most likely to provide OSAT in areas with more minorities and higher income, while non-profits are most likely to enter markets with lower incomes and a large share of whites.

The remainder of the paper is organized as follows. Section 2 presents background on the relationship among public, non-profit, and for-profit provision of OSAT services. We then describe the data we use in the study. Section 4 presents the behavioral model and our assumptions on the data generating process, i.e., our notion of equilibrium. Section 5 discusses the estimation and Section 6 presents the empirical results. The final section concludes.

\section{OSAT institutional background}

OSAT is an appropriate and important area for studying strategic interaction among different types of organizations. An estimated 22 million Americans (9.4\% of adults) were classified as having a substance abuse disorder in 2001, and 3.5 million received some kind of treatment. ${ }^{8}$ Substance abuse treatment is a large market, with $\$ 18$ billion spent on treating substance abuse disorders in the United States during 2001. The demand for treatment options is increasing as public support for treatment (rather than punishment) broadens and the number of substance abusers continues to grow. ${ }^{9}$ Over half of all funding for substance abuse treatment is public. State and local governments provide $38 \%$ of all substance abuse treatment funding, while Medicaid comprises

\footnotetext{
${ }^{7}$ The probabilities are the bounds of a $95 \%$ confidence interval based on our empirical model.

${ }^{8}$ See Substance Abuse and Mental Health Services Administration (SAMHSA, 2004).

${ }^{9}$ Mark et al. (2005) estimate that spending on substance abuse treatment increased an average of $4.6 \%$ per year between 1996 and 2001. They also provide an extensive discussion of expenditures on substance abuse treatment.
} 
another $19 \%$. Treatment services are provided by a variety of types of organizations. In addition to public providers, which represented $14 \%$ of U.S. treatment facilities in 2003, non-profit and for-profit organizations accounted for approximately $61 \%$, and $25 \%$ of all treatment facilities, respectively.

There is some evidence that ownership structure is correlated with the types of services offered. For example, Wheeler and Nahra (2000) find that for-profit clinics treat a larger proportion of heroin addicts and a smaller proportion of alcohol abusers than non-profit and government clinics. ${ }^{10}$ Within the non-profit group, a potential distinction exists between clinics that do and do not receive earmarked public support. ${ }^{11}$ These earmarks may take the form of per-patient or lump sum subsidies, via either direct monies or in-kind subsidies such as building space (which, anecdotal evidence suggests, is quite common). ${ }^{12}$ Clinics that accept earmarked support are also subject to a greater degree of government supervision. While our data allow us to determine whether a clinic receives earmarked support $-85 \%$ of the non-profits in our sample receive earmarked public support - unfortunately, it does not tell us the extent of such support. Our model (discussed below) could be misspecified if non-profit clinics that did not accept earmarks behaved more like for-profit clinics, for example. ${ }^{13}$

While the common interpretation of substance abuse "rehab" often is of treatment in an inpatient (residential) setting, far more treatment programs provide outpatient services. ${ }^{14}$ Clinics of all ownership types are active in the provision of OSAT. In this paper we infer the payoff functions for these different types of organizations based on their observed responses to exogenous market characteristics and the presence of clinics of other types. In executing our analysis, we make an assumption regarding the uniformity of government clinics. While we assume that all government clinics share identical ex ante payoff functions, actual public clinics may be operated by a state government (26\% of public clinics); a local, county, or community government (55\%); or the federal government (19\%). Although we recognize there may be differences in decision making for clinics

\footnotetext{
${ }^{10}$ Sindelar and Olmstead (2005) find that managed care causes for-profits to offer more services and public clinics to offer fewer services.

${ }^{11}$ A small fraction of for-profit clinics also report receiving public earmarks. Heinrich and Fournier (2004) find that the degree of publicness (percentage of total revenues received from public funding) and ownership status may affect some of the patient outcomes, but the effects are small.

${ }^{12}$ We acquired institutional details on earmarks via a phone conversation with Alan Rochlin, former director of Second Genesis, a multi-facility non-profit substance abuse rehabilitation program in the Washington, D.C. area.

${ }^{13}$ As a robustness check, therefore, we also estimated a model for which we grouped non-profit clinics not receiving earmarks together with for-profit clinics. The results, which are similar to our base model, are available from the authors upon request.

${ }^{14}$ In 2003 , only $7.4 \%$ of facilities were a part of hospital inpatient substance abuse services and $27.8 \%$ of facilities offered residential (nonhospital) substance abuse services. Outpatient substance abuse services were available at $80 \%$ of clinics.
} 
at different levels of government, we are more concerned with the question of public versus private provision of OSAT. Because our empirical method employs only minimal assumptions on the form of the game (and on equilibrium selection), some differences across public clinics are implicitly accommodated within our model.

\section{Data}

We use data on the location and characteristics of OSAT facilities from the 2003 National Survey of Substance Abuse Treatment Services (N-SSATS), an annual census of substance abuse treatment facilities conducted by the Substance Abuse and Mental Health Services Administration (SAMHSA). The information provided by N-SSATS includes facility ownership structure and the types of services offered. In 2003, there were 13,623 eligible respondent facilities included in the survey. ${ }^{15}$ Most clinics (61\%) identify substance abuse treatment as the facility's primary focus, and $26 \%$ report a mix of substance abuse and mental health treatment services. Clinics of different ownership types vary in the payment forms they receive. ${ }^{16}$

We model the decision to offer OSAT in a distinct geographic area. We focus on the 1,702 U.S. counties with populations between 5,000 and 100,000 that are not within in a Metropolitan or Consolidated Statistical Area (MSA or CSA). We assume that treatment markets are defined by county borders. There are four considerations that motivate our focus on these counties along with the market definition. First, most of the public funding for OSAT is contributed by local governments. Second, populations in counties outside of urban areas tend to be more isolated, and by its very nature OSAT patients do not travel long distances to receive treatment. This implies that our market definitions are relatively unlikely to be affected by patients travelling across market borders. Third, substance abuse is a major public health issue in many rural areas, and the smallness of these markets may lead to the complete absence of OSAT services or a relatively narrow variety of treatment options. We return to this topic in Section 6.3.3. Finally, it is computationally prohibitive to estimate our model in markets with a very large number of decision makers of each ownership type. ${ }^{17}$

\footnotetext{
${ }^{15}$ A total of 17,787 facilities were believed to offer substance abuse treatment services. However, $15 \%$ were found to be ineligible for the survey because they had closed, were not providing substance abuse treatment on March 31 , 2003 , or treated incarcerated clients only. Of the remaining facilities, about $95 \%$ completed the N-SSATS survey. Many of these facilities are in large metropolitan areas, and thus outside of the scope of the present paper.

${ }^{16}$ For example, $69.7 \%$ percent of non-profits accept Medicaid for payment, but only $33.5 \%$ of for-profits clinics accept Medicaid. Cash or self-payment is accepted at $99.1 \%$ percent of for-profit clinics but only $79.8 \%$ of public clinics.

${ }^{17} \mathrm{~A}$ focus on smaller markets is common in the empirical entry literature, and especially so in papers that employ
} 


\subsection{Summary statistics}

Of the 1,702 counties in our sample, approximately $30 \%$ have no OSAT services while about $40 \%$ have a single clinic and $18 \%$ have two clinics. In our empirical analysis, we consider three types of organization. We denote government entities as type $G$, private non-profits as $N$ and private forprofits as type $F$. Non-profit clinics are the most common, appearing in almost $40 \%$ of all markets. Fewer than $5 \%$ of markets in the sample have more than two non-profit clinics. To simplify our analysis we collect all markets with two or more non-profit clinics and treat them as being identical, so that the possible outcomes for type $N$ clinics are in $\{0,1,2+\}$. Type $G$ and $F$ clinics are less common than non-profits, and we truncate the clinic count at one for public and for-profit facilities. Government clinics appear in $20 \%$ of the markets in the sample, while for-profit clinics are in $13 \%$ of markets. In Table 1 we describe the frequency of different clinic configurations in the data. Among the markets with clinics, the most common configuration (25.6\%) is a single non-profit clinic and no other clinics. The least common configuration has one public, one for-profit, and two non-profit clinics, which occurs in $1.29 \%$ of all markets.

In Table 2 we provide summary statistics on the mean demographic characteristics of the sample counties, plus details on how the mean characteristics vary with the total number of OSAT clinics in a market. ${ }^{18}$ These features of the data may reflect a greater incidence of substance abuse among these portions of the population, a greater likelihood of seeking treatment conditional on a substance abuse problem, ability to pay, or voter preferences. As expected, counties with larger populations support more clinics. The number of clinics also appears to increase in the percentage of residents who are white and decrease in the male median age. An additional market characteristic likely to be related to OSAT demand is the percentage of divorced females, which we interpret as a measure of household discord. We also include the number of nurses per 10,000 residents to capture supply side effects. We conjecture that markets with a high supply of nurses will have relatively low operating costs. Finally, to account for state-level variation in political and regulatory attitudes toward for-profit and non-profit medical providers, we calculate the share of all medical hospitals in the county's state that are for-profit.

econometric methods similar to those described in Section 4.

${ }^{18}$ The demographic data were downloaded from the U.S. Census Bureau and the Area Resource File. 


\subsection{Descriptive analysis}

We estimate probit and ordered probit models to examine how the presence of each type of clinic is correlated with the number of remaining clinics of various types and the demographic variables. Let $n_{t}$ denote the (truncated) number of clinics of type $t$, with $t \in\{G, N, F\}$. The vector of clinic counts other than type $t$ is $\mathbf{n}_{-t}$. We report in Table 3 that the presence of a government clinics is negatively correlated with the presence of the first non-profit, but a second non-profit clinic or a for-profit clinic does not significantly affect the probability that $n_{G}=1$. The results also show that non-profit clinics are negatively and significantly affected by the presence of government clinics but not for-profit clinics. Finally, the probability that a market contains a for-profit clinic is not significantly correlated with $n_{G}$ or either the first or second non-profit clinic. Most demographic variables have a significant effect on $n_{t}$ in the anticipated direction. An interesting exception is the racial composition of a market. A greater percentage of white residents has a positive effect on types $N$ and $F$ clinics, but a negative and significant effect on the presence of government clinics. ${ }^{19}$

While these descriptive results are suggestive of the relationships among types of clinics, the parameter estimates should be read cautiously. If clinics of different types respond strategically to each other, then the values of $\mathbf{n}=\left[n_{G}, n_{N}, n_{F}\right]$ are endogenous in each model. Further, the strategic effects are biased if there is correlation among the type-specific error terms since common shocks that induce all types to offer OSAT will increase the probability that each type of clinic enters a market.

\section{Model}

In this section, we present a model to characterize the behavior of the three potential OSAT provider types. We assume that each clinic type has a payoff function that governs its decision whether to be active in a market. A clinic chooses to be active when the payoff from doing so is positive, and it chooses to be inactive when participating would result in a negative payoff. Each type's payoff function depends on the decisions made by other agents in the market, and different types of clinics may be affected differently by each type of potential competitor. The reduced-form payoff function has a different interpretation for each type of clinic. While the for-profit clinics likely pursue profit maximization, public and non-profit clinics may have other goals. For example,

\footnotetext{
${ }^{19}$ There are several demographic variables that one might consider adding to the analysis. We have experimented with additional variables (e.g., income, presidential voting patterns) but found that they do not significantly improve the fit of these basic models or the full structural model described below. To keep the empirical analysis tractable, we opt for a parsimonious set of exogenous variables.
} 
government participation could be responsive to tax revenues or political pressure for rehab services, with this pressure increasing when no private clinics are present.

We assume that every market is populated by potential OSAT providers of each type. The payoff function for a type $t$ clinic that participates in market $m$ has the following form: ${ }^{20}$

$$
\pi_{t m}\left(n_{t}, \mathbf{n}_{-t}, X_{m}, \varepsilon_{t m} ; \theta_{t}\right)=\bar{\pi}_{t m}\left(n_{t}, \mathbf{n}_{-t}, X_{m} ; \theta_{t}\right)+\varepsilon_{t m}
$$

Payoffs are zero for all potential clinics which remain out of the market. $X_{m}$ is a set of market characteristics that affect the payoff associated with operating a clinic, and $\theta_{t}$ is the vector of payoff function parameters for each type. Both $X_{m}$ and $\theta_{t}$ are known to all potential clinics. Each payoff function has a component, $\varepsilon_{t m}$, that is unobserved by the econometrician but common knowledge for all decision makers in the market. We assume that the $\varepsilon_{t m}$ values are independent of $X_{m}$. In some discussion below we suppress the dependence of $\pi_{t m}$ on all factors except for the number of clinics for notational convenience. We write $\pi_{t m}\left(n_{t}, \mathbf{n}_{-t}\right)$ to indicate the payoff from $n_{t} \in\{1,2\}$ type $t$ clinics operating in market $m$ with a collection of competitors described by the vector $\mathbf{n}_{-t}$. By assumption, $\pi_{t m}\left(0, \mathbf{n}_{-t}\right)=0$. Where possible, we also suppress the market indicator $m$ in subscripts.

\subsection{Parameterized payoff functions}

We assume that agents' (i.e., potential clinics') payoffs from offering OSAT takes the following form:

$$
\begin{aligned}
\pi_{t m}\left(n_{t}, \mathbf{n}_{-t}\right) & =\bar{\pi}_{t m}\left(n_{t}, \mathbf{n}_{-t}\right)+\varepsilon_{t m} \\
& =X_{m} \beta_{t}+\sum_{s \neq t} \delta_{t s} 1\left[n_{s} \geq 1\right]+\gamma_{t N} 1\left[n_{N}=2\right]+\varepsilon_{t m} \\
\text { with } \varepsilon_{t m} & =u_{m}+\eta_{t m} .
\end{aligned}
$$

Through the type-specific parameter vector $\beta_{t}$, the $X$ variables are permitted to have different effects on different types of agents. The data in $X$ captures the size of the "market" for OSAT, plus potential demand and cost shifters. The strategic interactions between clinics are in the $\delta$ s and $\gamma_{\mathrm{s}}$. A negative $\delta_{G F}$, for example, implies that offering OSAT is less attractive to a local government if OSAT is being offered by a for-profit clinic. A negative $\delta_{F G}$ implies that offering OSAT is less attractive to a for-profit clinic if OSAT is already offered by a public clinic. The

\footnotetext{
${ }^{20}$ This is the payoff function considered in Mazzeo (2002). Like Mazzeo, we have assumed that the payoffs are the same for agents of the same type offering OSAT within a given market. Since few markets have more than one of any type of firm, this assumption is relatively innocuous.
} 
parameter $\gamma_{t N}$ captures the additional effect of a second $N$ clinic on the payoff to a type $t$ clinic. Note that there is also a $\gamma_{N N}$ term reflecting the effect of one $N$ program on the payoffs of the other $N$ clinic. Finally, we specify that $\varepsilon$ includes market- and type-specific benefits (or costs) which are observed by all potential clinics but unobserved by the econometrician. The first term, $u_{m}$, is a market-specific unobservable that is identical across all agents in the market. This market-specific error is important since there may be unobserved factors which shift the return from operating a clinic of any type. The second term, $\eta_{t m}$, is a type-specific unobservable that is iid across types and markets, and independent of $u_{m}$. Both $u$ and $\eta$ are distributed $N(0,1)$. In principle, it is possible to identify the variance of $u_{m}$ relative to the variance of $\eta_{t m}$. This is difficult in practice, however, and for convenience we assume that the variances are equal. ${ }^{21}$

\subsection{Equilibrium and the data generating process}

The form of the payoff function does not place restrictions on the relative impact of one type of clinic on another. Similarly, we make minimal assumptions about the data generating process (DGP) that determines the observed outcomes. While our approach complicates estimation, it allows for a rich characterization of the behavior of each type of agent.

While we do not directly observe the payoffs for each type of decision maker, we do observe the number of clinics of each type as well as the market's demographic characteristics. The empirical approach involves drawing inferences about latent payoff values under the assumption that the observed outcomes are the result of agents' optimal decisions given their particular payoff functions. That is, we assume that each type of agent chooses to operate a clinic if and only if its payoffs from doing so are non-negative. This assumption places a set of inequality restrictions on the latent payoff functions that must be true for each observed market structure. The stochastic specification of the payoffs translates these conditions into restrictions on $\varepsilon$. For a particular observed value of $\mathbf{n}$, the following conditions must hold:

$$
\begin{aligned}
& \pi_{t m}\left(1, \mathbf{n}_{-t}\right)<0 \text { if } n_{t}=0 \\
& \pi_{t m}\left(1, \mathbf{n}_{-t}\right) \geq 0 \text { if } n_{t}=1
\end{aligned}
$$

Condition 1 (C1) states that any agent who chooses not to offer OSAT would have earned a negative payoff if they operated an OSAT clinic, given the actions of the other agents. Condition 2 states that all agents who choose to operate a clinic earn a positive payoff. There are two additional

\footnotetext{
${ }^{21}$ This is the same assumption employed by Ciliberto and Tamer (2006) and Jia (2006). In a model with a different approach to equilibrium, Berry (1992) is able to identify the relative variance of the market specific unobservable.
} 
conditions for non-profit clinics:

$$
\begin{aligned}
& \pi_{N m}\left(2, \mathbf{n}_{-N}\right)<0 \text { if } n_{N}=1 \\
& \pi_{N m}\left(2, \mathbf{n}_{-N}\right) \geq 0 \text { if } n_{N}=2
\end{aligned}
$$

When there is only one $N$ clinic, in addition to $\mathrm{C} 2$ it also must be true that a second $N$ clinic would have earned a negative payoff (C3). Finally, C4 states that when there are two $N$ agents operating OSAT, both must earn positive payoffs. Together, conditions C1-C4 guarantee that each agent which chooses to operate a clinic earns a positive payoff, while any agent which chooses not to operate a clinic would have earned a negative payoff had they chosen to offer OSAT.

These behavioral assumptions are an intuitive yet minimal set of conditions that correspond to a Nash equilibrium in entry strategies. The conditions are appealing because we would expect them to hold in each period across a wide variety of possible entry games. While the conditions are necessary for a pure strategy Nash equilibrium of a simultaneous-move entry game, the game always admits multiple equilibria as long as the $\varepsilon$ s have infinite support. ${ }^{22}$ We could assume a mechanism that selects from the equilibria as in Bresnahan and Reiss (1990), Berry (1992), Mazzeo (2002) and others. This would require additional restrictions on both the payoffs and the game itself. Such restrictions could insure that only one $\mathbf{n}$ satisfies all of the inequalities for a given set of parameters. Since we believe that multiple equilibria are likely to be present in this particular institutional setting, we specify a model that is capable of handling this multiplicity.

\section{Estimation}

We now discuss an estimation approach that follows from our assumption that agents make optimal decisions given their respective payoff functions. The approach is based on Ciliberto and Tamer (2006), and it explicitly incorporates the presence of multiple equilibria without requiring any assumptions about equilibrium selection. Without supplementing C1-C4 with additional assumptions, it is not possible to use conventional econometric techniques (such as maximum likelihood) to estimate $\theta$. The equilibrium conditions do not yield exact probabilities for an outcome $\mathbf{n}$ when there is a distinct $\mathbf{n}^{\prime}$ which also satisfies C1-C4. That is, the likelihood is not well-defined for outcomes which can occur as multiple equilibria. This is generically true of any outcome that involves a positive number of clinics (excluding the outcome in which each type operates the maximum possible number of clinics for that type).

\footnotetext{
${ }^{22}$ See Bresnahan and Reiss (1990), and Cohen and Manuzsak (2005) for graphical representations of possible multiplicity in a variety of entry games.
} 
For a given set of parameters, however, it is possible to define upper and lower bounds on the probability that the observed outcome, $\mathbf{n}^{*}$, satisfies the assumptions of the DGP. The upper bound is the probability that a vector $\varepsilon$ is drawn such that $\mathbf{n}^{*}$ satisfies the inequalities in C1-C4 regardless of whether any other outcomes satisfy the inequalities. The lower bound is the probability that an $\varepsilon$ is drawn such that $\mathbf{n}^{*}$ is the only outcome that satisfies C1-C4. Put differently, the upper and lower bounds represent opposite treatments of how multiplicity is resolved in favor or against $\mathbf{n}^{*}$. These bounds are the basis of our estimation strategy.

We write the upper bound on the probability of observing $\mathbf{n}^{*}$ by assuming that $\mathbf{n}^{*}$ always obtains in the region of multiplicity:

$$
\bar{P}\left(\mathbf{n}^{*} \mid X ; \theta\right)=\operatorname{Pr}\left(\mathrm{C} 1-\mathrm{C} 4 \text { hold for } \mathbf{n}^{*} \mid X ; \theta\right)
$$

We then compute the lower bound on the probability by assuming that $\mathbf{n}^{*}$ never occurs in the region of multiplicity:

$$
\underline{P}\left(\mathbf{n}^{*} \mid X ; \theta\right)=\operatorname{Pr}\left(\begin{array}{c}
{\left[\mathrm{C} 1-\mathrm{C} 4 \text { hold for } \mathbf{n}^{*} \mid X ; \theta\right] \cap} \\
{\left[\mathrm{C} 1-\mathrm{C} 4 \text { does not hold for any } \mathbf{n} \neq \mathbf{n}^{*}\right]}
\end{array}\right) .
$$

These bounds imply a set of inequality restrictions. In particular, we know that the true probability of observing $\mathbf{n}^{*}$ must lie between the upper and lower bounds as predicted by our model:

$$
\underline{P}\left(\mathbf{n}^{*} \mid X ; \theta\right) \leq P\left(\mathbf{n}^{*} \mid X\right) \leq \bar{P}\left(\mathbf{n}^{*} \mid X ; \theta\right) .
$$

The term $P\left(\mathbf{n}^{*} \mid X\right)$ is the population probability of observing $\mathbf{n}^{*}$ given the set of $X$ variables in a particular market. $P\left(\mathbf{n}^{*} \mid X\right)$ implicitly depends on the distribution of unobserved market characteristics as well as any equilibrium selection mechanism. We do not know $P\left(\mathbf{n}^{*} \mid X\right)$, so we replace it with a consistent estimate, $\widehat{P}\left(\mathbf{n}^{*} \mid X\right)$, obtained from our sample. We discuss the estimate $\widehat{P}\left(\mathbf{n}^{*} \mid X\right)$ below.

We employ a modified minimum distance (MMD) estimator to find the $\widehat{\theta}$ for which the following restrictions are most nearly satisfied in our sample:

$$
\underline{P}\left(\mathbf{n}^{*} \mid X ; \widehat{\theta}\right) \leq \widehat{P}\left(\mathbf{n}^{*} \mid X\right) \leq \bar{P}\left(\mathbf{n}^{*} \mid X ; \widehat{\theta}\right)
$$

Our objective function is a distance measure that penalizes values of $\theta$ that fail to satisfy the inequalities above. Whenever the inequalities are satisfied, a market's contribution to the objective function is zero. When an inequality is violated, the market's contribution is the square of the 
distance between $\widehat{P}\left(\mathbf{n}^{*} \mid X\right)$ and the nearest bound. Thus, $\widehat{\theta}$ is:

$$
\widehat{\theta}=\arg \min _{\theta} Q(\theta)=\sum_{m=1}^{M} Q_{m}(\theta)
$$

where

$$
\begin{aligned}
Q_{m}(\theta)= & 1\left[\widehat{P}\left(\mathbf{n}_{m}^{*} \mid X_{m}\right)<\underline{P}\left(\mathbf{n}_{m}^{*} \mid X_{m} ; \theta\right)\right] \times\left[\widehat{P}\left(\mathbf{n}_{m}^{*} \mid X_{m}\right)-\underline{P}\left(\mathbf{n}_{m}^{*} \mid X_{m} ; \theta\right)\right]^{2} \\
& +1\left[\widehat{P}\left(\mathbf{n}_{m}^{*} \mid X_{m}\right)>\bar{P}\left(\mathbf{n}_{m}^{*} \mid X_{m} ; \theta\right)\right] \times\left[\widehat{P}\left(\mathbf{n}_{m}^{*} \mid X_{m}\right)-\bar{P}\left(\mathbf{n}_{m}^{*} \mid X_{m} ; \theta\right)\right]^{2} .
\end{aligned}
$$

$1[\cdot]$ is the indicator function. The value $\widehat{\theta}$ minimizes the sum of squared differences between the population probabilities and the probability bounds from the model. We use a simulated annealing algorithm to search over $\theta$ values and minimize $Q(\theta)$.

Before presenting our results, we provide some additional details about the estimation procedure. First, we discuss the "first stage" estimates of $\widehat{P}\left(\mathbf{n}_{m}^{*} \mid X_{m}\right)$. Second, we discuss the concept of set identification since multiple $\theta$ s can be consistent with C1-C4 and the data. Finally, we discuss our algorithm for computing $\underline{P}\left(\mathbf{n}_{m}^{*} \mid X ; \widehat{\theta}\right)$ and $\bar{P}\left(\mathbf{n}_{m}^{*} \mid X ; \widehat{\theta}\right)$.

\subsection{First stage estimator}

The probability $\widehat{P}\left(\mathbf{n}_{m}^{*} \mid X\right)$ is strictly a function of the data, while the bounds $\bar{P}\left(\mathbf{n}_{m}^{*} \mid X_{m} ; \theta\right)$ and $\underline{P}\left(\mathbf{n}_{m}^{*} \mid X_{m} ; \theta\right)$ depend on the data, the parameters, and our assumptions on how the data are generated (i.e., our model and solution concept). There are many options for how $\widehat{P}\left(\mathbf{n}^{*} \mid X\right)$ may be obtained. In principle it could be obtained nonparametrically, but we opt for a flexible functional form. In our implementation of the model, we use a multinomial logit model to obtain estimates of $\widehat{P}\left(\mathbf{n}^{*} \mid X\right) .{ }^{23}$ These probabilities describe the way in which market structures vary with the market characteristics, but they do not provide information about the "structural" parameters that describe agents' incentives. $\widehat{P}\left(\mathbf{n}^{*} \mid X\right)$ is linked to $\theta$ through the economic model and equilibrium concept. If the equilibrium concept were such that there were always a unique equilibrium outcome, the upper and lower bounds given by the model would be equivalent since whenever $\mathbf{n}^{*}$ is observed, it must be the unique equilibrium. In this case, the conditional outcome probabilities in the population should equal the probabilities from the structural model at the true $\theta$. Then we could form a estimator by minimizing the distance between $\widehat{P}\left(\mathbf{n}^{*} \mid X\right)$ and $\bar{P}\left(\mathbf{n}_{m}^{*} \mid X_{m} ; \theta\right)=\underline{P}\left(\mathbf{n}_{m}^{*} \mid X_{m} ; \theta\right)$. Since our model admits multiple equilibria, there is not a one-to-one relationship between $\widehat{P}\left(\mathbf{n}^{*} \mid X\right)$ and

\footnotetext{
${ }^{23}$ Our use of a logit estimator for these conditional probabilities is similar to Heckman et al. (1998) and Ciliberto and Tamer (2006).
} 
the predictions of the model. Tamer (2003) demonstrates, however, that the relationship between $\widehat{P}\left(\mathbf{n}^{*} \mid X\right)$ and the model's probability bounds are still sufficiently informative to permit estimation of $\theta$.

\subsection{Set identification}

The inequalities that define the DGP may be satisfied by more than one $\theta$ in the population. Suppose, for example, that at the true $\theta$ :

$$
\underline{P}\left(\mathbf{n}^{*} \mid X ; \theta\right)<P\left(\mathbf{n}^{*} \mid X\right)<\bar{P}\left(\mathbf{n}^{*} \mid X ; \theta\right)
$$

in every market. Then, as long as $\underline{P}\left(\mathbf{n}^{*} \mid X ; \theta\right)$ and $\bar{P}\left(\mathbf{n}^{*} \mid X ; \theta\right)$ are continuous in $\theta$, it is possible to perturb $\theta$ by an small amount and stay inside the bounds. Thus, the true $\theta$ cannot be distinguished from the perturbed $\theta$. Only under special circumstances can one show that $\theta$ is point identified. ${ }^{24}$ In our setting, we can identify only the set of $\theta$ s that are consistent with C1-C4. These conditions essentially exclude values of $\theta$ that are not consistent with the model and data, which in turn yields a set of $\theta$ s that could have generated the observed data. Ciliberto and Tamer (2006) refer to the collection of $\theta \mathrm{s}$ that are consistent with the model's restrictions as the "identified set," and they prove that the MMD estimator provides a consistent estimate of the identified set. Statistical inference requires constructing confidence intervals for the identified set rather than for a particular $\theta$. We follow the method proposed by Chernozhukov, Hong and Tamer (2007) to calculate the confidence intervals. ${ }^{25}$ The interval, denoted by $\Theta_{\alpha}$, is a collection of $\theta$ s constructed so that they cover the identified set with the desired probability, $\alpha$. The interval is the set of parameters for which the objective function is within a specific neighborhood, $c_{\alpha}$, of the minimized objective function. That is,

$$
\Theta_{\alpha}=\theta: Q(\theta)-Q(\widehat{\theta}) \leq c_{\alpha}
$$

In the appendix we describe the method for finding the appropriate value of $c_{\alpha}$ as well as other computational details for inference on the identified set.

\subsection{Simulation of probability bounds}

Computing the upper and lower probability bounds of observing $\mathbf{n}^{*}$ involves finding the regions of $u_{m}$ and $\eta_{t m}$ in which $\mathbf{n}^{*}$ is an equilibrium and the regions in which $\mathbf{n}^{*}$ is the unique equilibrium.

\footnotetext{
${ }^{24}$ These circumstances are that a sufficient number of bounds given by the model collapse to a point, i.e., that some outcomes only occur as unique equilibria. See Tamer (2003) and Borzekowksi and Cohen (2005).

${ }^{25}$ An alternative method for computing confidence intervals is described in Andrews, Berry, and Jia (2004).
} 
We must re-calculate these bounds at each evaluation of the objective function. It is exceedingly difficult to compute the probability bounds analytically because the limits of integration are defined by restrictions that the model places on $u_{m}$ and $\eta_{t m}$. Therefore, we use simulation methods to obtain estimates of the upper and lower probability bounds. We begin by taking random draws of the market-level unobservable, $u_{m}$. For each draw, $u_{m}^{d}$, we define the region of each of the type-specific unobservables for which $\mathbf{n}_{m}^{*}$ is an equilibrium. In particular, for each $t$

$$
\begin{aligned}
& A_{t m}^{d}(\theta)=\eta_{t m}: \bar{\pi}_{t m}\left(n_{t}, \mathbf{n}_{-t} ; \theta\right)+u_{m}^{d}+\eta_{t m} \geq 0 \text { if } n_{t m} \geq 1 \\
& A_{t m}^{d}(\theta)=\eta_{t m}: \bar{\pi}_{t m}\left(1, \mathbf{n}_{-t} ; \theta\right)+u_{m}^{d}+\eta_{t m} \leq 0 \text { if } n_{t m}=0 \\
& A_{t m}^{d}(\theta)=\eta_{N m}: \bar{\pi}_{t m}\left(2, \mathbf{n}_{-t} ; \theta\right)+u_{m}^{d}+\eta_{t m} \leq 0 \text { if } n_{N m}=1 .
\end{aligned}
$$

Let $F(\eta)$ represent the joint distribution function of $\eta=\left(\eta_{G m}, \eta_{N m}, \eta_{F m}\right)$, with $A_{m}^{d}$ as the union of each type's $A_{t m}^{d}$. Then, conditional on a draw $u_{m}^{d}$, the upper bound is

$$
\bar{P}^{d}\left(\mathbf{n}^{*} \mid X ; \theta\right)=\int_{A_{m}^{d}} d F(\eta) .
$$

This integral can be computed numerically, due to the independence $\eta_{t m} \mathrm{~s}$. We then simulate the upper bound, $\bar{P}\left(\mathbf{n}^{*} \mid X ; \theta\right)$, by averaging the values of $\bar{P}^{d}\left(\mathbf{n}^{*} \mid X ; \theta\right)$ across $D$ simulation draws of $u_{m}^{d}$ :

$$
\widetilde{\bar{P}}\left(\mathbf{n}^{*} \mid X ; \theta\right)=\frac{1}{D} \sum_{d=1}^{D} \bar{P}^{d}\left(\mathbf{n}^{*} \mid X ; \theta\right) .
$$

To compute $\underline{P}\left(\mathbf{n}^{*} \mid X ; \theta\right)$, we use the fact that the lower bound can be written:

$$
\begin{aligned}
\underline{P}\left(\mathbf{n}^{*} \mid X ; \theta\right)= & \operatorname{Pr}\left(\mathbf{n}^{*} \text { uniquely satisfies C1-C4 }\right) \\
= & \operatorname{Pr}\left(\mathbf{n}^{*} \text { uniquely satisfies C1-C4 } \mid \mathbf{n}^{*} \text { satisfies C1-C4 }\right) \\
& \times \operatorname{Pr}\left(\mathbf{n}^{*} \text { satisfies } \mathrm{C} 1-\mathrm{C} 4\right)
\end{aligned}
$$

For a given simulation draw, $u_{m}^{d}$, from the the distribution of $u_{m}$, we have already computed

$$
\operatorname{Pr}\left(\mathbf{n}^{*} \text { satisfies } \mathrm{C} 1-\mathrm{C} 4\right)=\bar{P}^{d}\left(\mathbf{n}^{*} \mid X ; \theta\right) \text {. }
$$

For each $u_{m}^{d}$, we then calculate the probability that $\mathbf{n}_{m}^{*}$ uniquely satisfies C1-C4, conditional on $\mathbf{n}_{m}^{*}$ satisfying C1-C4. That is, conditional on the outcome of interest being an equilibrium, we determine whether there are any additional pure strategy equilibria. We draw from the region of $\eta$ in which $\mathbf{n}_{m}^{*}$ is an equilibrium, $A_{m}^{d}(\theta)$. We then check whether the outcome of interest is the 
only outcome for which C1-C4 holds for the simulated $u$ and $\eta \cdot{ }^{26}$ Our simulation estimator for $\underline{P}\left(\mathbf{n}^{*} \mid X ; \theta\right)$ is

$$
\underline{\widetilde{P}}\left(\mathbf{n}^{*} \mid X ; \theta\right)=\frac{1}{D} \sum_{d=1}^{D} \frac{1}{S} \sum_{s=1}^{S} 1\left[\mathbf{n}^{*} \text { uniquely satisfies C1-C4 } \mid \eta_{m}^{s} \in A_{m}^{d}(\theta)\right] \times \bar{P}^{d}\left(\mathbf{n}^{*} \mid X ; \theta\right) .
$$

The independence of $\eta_{t m}$ and $u_{m}$ implies that we may set $S=1$. Fixing $S=1$ and letting $D$ go to infinity is asymptotically equivalent to allowing both $D$ and $S$ to increase without bound.

\section{Results}

\subsection{Estimates of the Identified Set}

In Table 4 we present our confidence intervals for the identified set. These intervals, denoted $\Theta_{95}$, are constructed so that they cover the identified set with $95 \%$ probability. $^{27}$ Since we can only identify the set of parameters consistent with the behavioral model and the data, we discuss most of our results in terms of $\Theta_{95}$. In addition, however, we present the values of $\theta$ which minimize the objective function and, in an abuse of terminology, we refer to these values as "point estimates."

The estimates of $\delta$ and $\gamma$, the competitive effects across clinics, are all negative, which indicates that each type of organization is a substitute for the others. According to the point estimates, government clinics are most strongly affected by the presence of the first non-profit $(N)$ clinic. The effect of a for-profit $(F)$ clinic is less than the first non-profit clinic, yet larger than the effect of the second non-profit clinic. ${ }^{28}$ This is consistent with the coefficient estimates from the probit analysis of Table 3. Non-profit clinics have strong effects on each other, government clinics have a slightly weaker effect on $N$ clinics and for-profit clinics have the smallest effect on non-profits. Finally, we note that both $N$ and $F$ clinics are affected negatively by the presence of government clinics, which contrasts with the probit analysis of Table 3 that implied for-profit clinics were not affected by the presence of $G$ or $N$ clinics. This may be due to market-level unobservables which affect all clinic types, represented by $u_{m}$ in our empirical model.

The estimated effects of demographic variables on payoff functions are largely consistent with the preliminary results reported in Table 3. All types of clinics are more likely to offer OSAT in

\footnotetext{
${ }^{26}$ Since this step is the most time intensive, our algorithm is fairly efficient because we eliminate the need to evaluate C1-C4 (for all the possible configurations) in the region where $\mathbf{n}^{*}$ is not an equilibrium. Furthermore, our importance sampling technique guarantees a non-zero derivative with respect to $\theta$, since the $\bar{P}^{d}\left(\mathbf{n}^{*} \mid X ; \theta\right)$ is continuous in $\theta$.

${ }^{27}$ The set itself is a collection of parameter vectors. In our results we present the interval for each of the model parameters. The identified set is, however, smaller than the union of the individual intervals.

${ }^{28}$ Other researchers have found similar effects of a second entrant in other markets (e.g. Mazzeo (2002) and Cohen and Mazzeo (2007)).
} 
markets with a large population and a large proportion of nurses. Private clinics (both non-profit and for-profit) are more likely to offer OSAT in markets with a greater percentage of white residents, while $G$ clinics are more likely to offer treatment in markets with larger minority populations. All types of clinics are more likely to offer OSAT in markets with high divorce rates and a lower male median age. Clinics of all types are also less likely to participate in markets within states that have a high share of for-profit hospitals.

Recall that the objective function $Q(\theta)$ assigns a penalty to an observation when the conditional population probability $P\left(\mathbf{n}_{m} \mid X_{m}\right)$ lies outside of the values of $\bar{P}\left(\mathbf{n}_{m}^{*} \mid X_{m} ; \theta\right)$ and $\underline{P}\left(\mathbf{n}_{m}^{*} \mid X_{m} ; \theta\right)$ implied by the model. A reasonable way to assess the performance of the empirical model is to ask how frequently we find that $\underline{P}\left(\mathbf{n}_{m}^{*} \mid X_{m} ; \widehat{\theta}\right)<P\left(\mathbf{n}_{m} \mid X_{m}\right)<\bar{P}\left(\mathbf{n}_{m}^{*} \mid X_{m} ; \widehat{\theta}\right)$ at the value of $\widehat{\theta}$ which minimizes $Q$. There are 612 markets in which the empirical probability, $P$, is bounded by the predicted probabilities. This is $36.0 \%$ of the 1,702 observations in the full sample, and $53.7 \%$ of the 1,139 observations for which theory permits different values of $\underline{P}$ and $\bar{P}$. For the remaining observations that do not fall within the bounds, the average difference between $P$ and $\bar{P}$ or $\underline{P}$ (as appropriate) is 3.77 percentage points. $^{29}$ When the value of $P$ falls outside of $[\underline{P}, \bar{P}]$, it is more often above $\bar{P}$ (598 out of 1069 observations) than below $\underline{P}$.

\subsection{Analysis of Multiplicity}

The negative estimates of the $\delta \mathrm{s}$ and the $\gamma \mathrm{s}$ imply that multiple outcomes satisfy $\mathrm{C} 1-\mathrm{C} 4$ with positive probability, excepting the extreme outcomes $(0,0,0)$ and $(1,2,1)$. For example, there is a positive probability that $(1,0,0),(0,1,0)$ and $(0,0,1)$ simultaneously satisfy C1-C4. It is also possible that there are multiple equilibria in which the total number of clinics differs across the outcomes. For example, a market that supports $(1,0,0)$ might also support $(0,1,1)$ and $(0,2,0)$ as equilibria. We analyze these different dimensions of multiplicity in several ways. First, we describe the overall pattern of multiplicity across the different outcomes. We then present a set of conditions on the $\delta$ and $\gamma$ parameters that are necessary for multiple equilibria involving different numbers of clinics. Finally, we evaluate the performance of a simple equilibrium selection mechanism and draw some conclusions about the actual selection.

In Table 5 we present the probabilities of alternate equilibria given the observed outcome, both for the point estimates $\widehat{\theta}$ and within the set $\Theta_{95}$. For example, on average the markets with con-

\footnotetext{
${ }^{29}$ For example, in a market for which we predict $\bar{P}\left(\mathbf{n}_{m}^{*} \mid X_{m} ; \widehat{\theta}\right)=0.2$, our first-stage estimates might indicate that $P\left(\mathbf{n}_{m} \mid X_{m}\right)=0.2377$.
} 
figuration $(1,0,0)$ have a probability of multiple equilibria between $35.1 \%$ and $55.7 \%$ according to $\Theta_{95}$. These probabilities should be interpreted as the chance that the vector $\left(\varepsilon_{G m}, \varepsilon_{N m}, \varepsilon_{F m}\right)$ supports an equilibrium other than $(1,0,0)$ conditional on $(1,0,0)$ being an equilibrium in the market. Averaging across all markets, the confidence interval on the identified set implies probabilities of multiple equilibria between $24.2 \%$ and $39.4 \%$, while the point estimates yield a multiplicity probability of $28.8 \%$. Overall, the chance of multiple outcomes satisfying C1-C4 strikes us as fairly large. This suggests that standard estimators using either maximum likelihood or method of moments would produce results that may be distorted by assumptions about equilibrium selection.

An appealing feature of our approach is that it is flexible enough to accommodate multiple outcomes involving different total numbers of clinics. In Table 6 we describe the conditions which are necessary and sufficient for observing particular configurations with different numbers of clinics. ${ }^{30}$ For example, consider the top row of the table which concerns the outcome $(1,0,0)$. There are two alternative outcomes with different total numbers of clinics which also may be equilibria in this case: $(0,1,1)$ and $(0,2,0)$. For the configuration $(0,1,1)$ to satisfy C1-C4, it must be true that the non-profit clinic has a higher payoff in a market with a for-profit clinic than a market with a public clinic. If this were not so, then a non-profit clinic would have participated in the market alongside the public clinic. Similarly, the for-profit clinic must earn a higher payoff facing a non-profit clinic than a government clinic. Turning to the $(0,2,0)$ outcome, it must be the true that both non-profit clinics have a higher payoff facing each other than when in a market with one public clinic. Within Table 6 the configurations in bold type signify outcomes for which the corresponding conditions are satisfied for at least one parameter vector in the set $\Theta_{95}$.

While our estimates indicate that it is important that we do not impose an ad hoc equilibrium selection rule, it is useful to consider a simple rule and evaluate its performance to get a broad sense of what selection mechanisms may be at work. ${ }^{31}$ We do this by simulating values of $\left(\varepsilon_{G m}, \varepsilon_{N m}, \varepsilon_{F m}\right)$ for each market and then evaluating which configurations satisfy conditions C1-C4. We draw values of $\varepsilon_{t m}$ so that a market's observed outcome is also a simulated equilibrium given a value of the parameter vector and the market's demographic characteristics. Once a market's set of equilibrium configurations is identified, we select among these equilibria with equal probability for each outcome. For example, in a market with two pure-strategy equilibria of $\mathbf{n}_{m}=(1,0,0)$ and $\mathbf{n}_{m}^{\prime}=(0,1,0)$ we select each equilibrium with probability 0.5 . In Table 7 we compare the market

\footnotetext{
${ }^{30}$ The conditions are both necessary and sufficient because we assume that the unobservables have infinite support.

${ }^{31} \mathrm{~A}$ more detailed approach to estimating the equilibrium selection is provided in Bajari, Hong and Ryan (2004).
} 
structures predicted under this rule with those observed in the data. Our metric is the number of markets in which a type $t$ clinic appears. ${ }^{32}$ Given the rule by which we simulate values of $\varepsilon_{t m}$, it must be the case that any unique outcome of the participation game is predicted perfectly for each combination of the parameter vector. This is apparent in the last row of the Table, which shows that there are 1,161 markets in the data that have at least one clinic, and this is captured exactly by the $95 \%$ confidence interval. ${ }^{33}$ The uniform selection mechanism performs well in replicating the number of markets in which type $N$ clinics appear. 836 markets in the data have non-profit clinics while our confidence interval is $[811.6,850.5]$. The mechanism, however, systematically overpredicts the number of markets with for-profit clinics while under-predicting public clinics. The magnitudes of over- and under-prediction are similar between the two types of clinic. According to the point estimates in Table 7, government clinics are under-predicted by 29.8 markets while for-profit clinics are over-predicted by 26.5 markets. This suggests that the actual (unobserved) equilibrium selection mechanisms in OSAT markets favor configurations with public clinics rather than for-profit clinics. While it is not possible to ascribe a welfare interpretation to these results, they do suggest an important trade-off between public and private clinics.

\subsection{Counterfactual experiments}

In this section we present results from counterfactual experiments. In each experiment, we remove clinics of a particular type and use our model to simulate the equilibrium responses of the two other types. We use the results from these experiments to answer three questions. First, to what extent do public clinics provide OSAT services that otherwise could be offered by a private (non-profit or for-profit) clinic? Second, how critical are the OSAT services provided by non-profit clinics (i.e., would similar services be provided by another type of clinic)? Third, what factors explain clinic participation in markets with a high likelihood of not having OSAT?

\subsubsection{Do Public Clinics Crowd Out Private Clinics?}

To evaluate whether government clinics provide OSAT services that otherwise could be offered by a private clinic, we simulate the removal of all public clinics from the markets in which they operate and then identify the equilibrium clinic configurations for the remaining clinic types. We begin

\footnotetext{
${ }^{32}$ It is also straightforward to compare the number of times in which each possible market structure is observed in the data and predicted by the model. These results are available from the authors on request.

${ }^{33}$ Since we are drawing from the region of the unobservables that rationalizes the observed outcome, $(0,0,0)$ is perfectly predicted. Therefore, the complement of $(0,0,0)$, i.e., at least one clinic of any type, is also perfectly predicted.
} 
by using the same uniform equilibrium selection rule employed above. In the first panel of Table 8 ("All Markets") we present results for the full sample. Using the collection of $\theta$ values in $\Theta_{95}$, the predicted number of markets with clinics falls by between $7.3 \%$ and $9.7 \%$ with the exit of all $G$ clinics. Both $N$ and $F$ clinics respond strongly to the removal of public clinics. In fact, in $69.2 \%$ of the markets there is some probability ( $5.5 \%$ on average with a maximum of $35 \%$ ) that the removal of a public clinic would result in two new clinics entering the market (using the point estimates). Furthermore, the point estimates imply that the expected number of markets with at least one non-profit clinic increases by 85 while the expected number of markets with a for-profit clinic increases by 96 . This is consistent with the parameter estimates in Table 4, which indicate that the effect of public clinics on for-profit payoffs is greater than the effect of type $G$ clinics on non-profits. This may be due to for-profit clinics being relatively sensitive about the presence of competitors. In summary, these results imply that if public officials closed all government clinics, complete replacement of these clinics might require additional subsidies in only a few cases.

While we estimate that most markets with public clinics would have these facilities replaced, the impact is not equal across markets. Recall from Table 4 that public clinics are more likely to offer OSAT care in markets with a relatively large minority population, while both types of private clinic have the opposite response to race. We therefore divide the markets by whether the percentage white population is above the median in our full sample (92.6\%). The remaining panels of Table 8 provide counterfactual results for each side of the median. We find that markets with a low proportion of whites are at substantially greater risk from losing all OSAT when public clinics close. The number of markets with clinics falls by between $11.6 \%$ and $14.9 \%$ for the parameter values in $\Theta_{95}$. In comparing the point estimates in Table 8, we note that $75 \%$ of all markets that lose OSAT entirely have a relatively large non-white population. Although the numbers of $N$ and $F$ clinics are predicted to increase for both sides of the median, the increases are proportionally greater in markets with more white residents. We further explore the effect of race on OSAT below.

\subsubsection{Which Are More Critical, Public or Non-Profit Clinics?}

While the calculations in Table 8 are somewhat sensitive to the equilibrium selection rule, we now present measures of OSAT replacement which do not depend on the selection rule. For configurations involving at least one public clinic or at least one non-profit clinic, we compute the average probability that no other type of clinic enters in response to the removal of either the type 
$G$ or type $N$ clinic. ${ }^{34}$ The average is taken over markets and simulation draws. Our results are in Table 9.

In the first row of the top panel of Table 9, we report that if all public clinics close, $45 \%$ of markets (103 of 228) with a single public clinic would be entirely without OSAT. The outcome is worse if a non-profit clinic is removed from a market with only a type $N$ clinic. In the first row of the lower panel, we report that $51 \%$ of these markets (222 of 435 ) would lose OSAT completely. In general across market configurations, removing a non-profit clinic is associated with a higher likelihood of a reduction in OSAT services. In the two configurations that involve both public and non-profit clinics, $(1,1,0)$ and $(1,2,0)$, removing an $N$ clinic is less likely to result in replacement entry than when a $G$ clinic is removed.

\subsubsection{Analysis of Marginal Markets}

To further assess differences in OSAT provision by public and private clinics, we designate a subset of our markets that are at risk for exclusion from OSAT. These marginal markets include: (a) all markets with no observed OSAT provision; and, (b) markets in which there is a single clinic and, according to $\widehat{\theta}$ and simulated values of $\varepsilon$, the probability of losing OSAT entirely is greater than $50 \%$ when the observed clinic is removed from the market. Using these criteria, we identify 892 markets as being marginal. While 541 of these markets are unserved by any OSAT provider, 99, 229, and 23 of these markets are served by a single public, non-profit and for profit clinic, respectively. We assess why OSAT is provided is some markets but not others, and what determines the type of OSAT clinic present. We evaluate the roles of race and median household income in determining OSAT provision. ${ }^{35}$

We estimate a multinomial logit model in which the dependent variable indicates whether a market has no clinics, a single $G$ clinic, a single $N$ clinic, or a single $F$ clinic. The no-OSAT outcome is treated as the base case. Our results, which are reported in Table 10, provide the marginal probabilities for the effects of $1 \%$ increase in the white population and a $\$ 1,000$ increase in median household income. ${ }^{36}$ We find that public clinics tend to operate in markets with more

\footnotetext{
${ }^{34}$ We do not present the results for the $(1,2,1)$ configuration since our assumptions imply that any exit would result in no additional entry.

${ }^{35}$ Although income is not among the $X$ variables in the empirical model, it is straightforward to merge income data into our sample. As discussed in footnote 19, we omit income from the base model because it appears to have no effect on outcomes in the full sample, given the inclusion of the other $X$ variables.

${ }^{36}$ We also estimated specifications that included median household income as well as: (1) the entire set of explanatory variables from the model; and (2) just population and race. In each specification we estimated, household income and race were statistically significant. The for-profit hospital share was the only other statistically significant variable; it was negative (positive) and significant for public (no) entry.
} 
minorities and higher income levels. This latter result may reflect the effects of the tax base on OSAT funding. Non-profit clinics, in contrast, tend to operate in poorer markets with larger white populations. While the tendency to operate in poorer markets suggests an altruistic bent to non-profits, we cannot exclude the possibility that governments in poorer areas might find that subsidizing OSAT through earmarks is a less expensive way to provide treatment. Although beyond the scope of this paper, a promising area of future research is to study whether altruistic objectives for non-profit (and even for-profit) clinics can be identified in the data.

\section{Conclusions}

This paper employs a model of endogenous market structure to study strategic behavior among public, private non-profit, and private for-profit healthcare providers. We specifically focus on the decision of outpatient substance abuse treatment clinics to be active within a market. We extend the literature on firms' entry decisions by reinterpreting firms' objective functions simply as payoff functions in the case of government and non-profit entities. Indeed, inference on the actual objective functions of these types of agents is of independent interest. By applying recently developed methods for estimating discrete games with multiple equilibria, we avoid imposing potentially ad hoc restrictions on payoffs. Our results appear to support our choice of method as we find multiple equilibria in both the identity and the number of clinics.

Our results demonstrate that differentiation among the three clinic types is important to understanding how OSAT is provided. We find that public clinics and non-profit entities (in addition to for-profits) take the actions of other players in the market into consideration in their operating decisions. Our counterfactual analysis indicates that there are many markets in which public clinics appear to prevent the entry of private clinics. By focusing on marginal markets where the chance of having zero OSAT is large, we explore the differing roles of public and private clinics. Within the marginal markets, public clinics are most likely to operate in markets with greater minority populations. However, the market must also have a sufficient income level ${ }^{37}$ for the public clinic to provide service. Non-profit clinics are more likely to operate in poorer markets with larger white populations. Thus, it appears that poorer markets with large minority populations are most likely to be unserved.

While our approach is informative about the nature of OSAT, this paper brings attention to several interesting questions that are nonetheless beyond its scope. In particular, in future work

\footnotetext{
${ }^{37}$ In another interpretation, this may represent a sufficient tax base.
} 
we intend to focus on (1) the interactions between inpatient and outpatient treatment; (2) the role of earmarks in the operation of non-profit clinics; and (3) the degree of patient overlap in public, non-profit and for-profit OSAT clinics. Finally, due to issues of model tractability, we focus on small markets. While OSAT provision in these markets is itself an important social and economic issue, our results are likely to be informative for larger markets as well. 


\section{References}

[1] Abraham, Jean Marie, Martin Gaynor and William Vogt (2006). Entry and Competition in Local Hospital Markets Journal of Industrial Economics, forthcoming.

[2] Andreoni, James. (1993). An Experimental Test of the Public-Goods Crowding-Out Hypothesis. The American Economic Review, 83(5): 1317-1327.

[3] Andrews, Donald, Steven Berry and Panle Jia (2004). Confidence Regions for parameters in discrete games with multiple equilibria with an application to discount store location. Yale Department of Economics Working Paper.

[4] Bajari, Patrick, Han Hong and Stephen Ryan (2004). Identification and Estimation of Discrete Games of Complete Information NBER Working Paper.

[5] Berry, Steven (1992). Estimation of a Model of Entry in the Airline Industry. Econometrica, 60(4): 889-917.

[6] Besley, Timothy and Stephen Coate (1991). Public Provision of Private Goods and the Redistribution of Income. The American Economic Review, 81(4): 979-984.

[7] Blomquist, Sören and Vidar Christiansen (1999). The Political Economy of Publicly Provided Private Goods. Journal of Public Economics, 73: 31-54.

[8] Borzekowski, Ron and Andrew Cohen (2005). Estimating Strategic Complementarities in Credit Unions' Outsourcing Decisions. Federal Reserve Board working paper.

[9] Bresnahan, Timothy and Peter Reiss (1990). Entry into Monopoly Markets. Review of Economic Studies, 57(4): 531-553.

[10] Bresnahan, Timothy and Peter Reiss (1991). Entry and Competition in Concentrated Markets. Journal of Political Economy, 99(5): 977-1009.

[11] Brown, Jeffrey and Amy Finkelstein (2006). The Interaction of Public and Private Insurance: Medicaid and the Long-Term Care Insurance Market. NBER Working Paper 10989.

[12] Chakravarty, Sujoy, Martin Gaynor, Steven Klepper and William Vogt (2006). The Evolution of the U.S. Hospital Industry. Health Economics, 15(4): 345-361. 
[13] Chernozhukov, Victor, Han Hong and Elie Tamer (2007). Parameter Set Inference in a Class of Econometric Models. Econometrica, forthcoming

[14] Ciliberto, Federico and Elie Tamer (2006). Market Structure and Multiple Equilibria in Airline Markets. University of Virginia working paper.

[15] Cohen, Andrew and Mark Manuzsak (2005). Endogenous Market Structure with Discrete Product Differentiation: An Analysis of Competition Between Banks and Thrifts. Federal Reserve Board working paper.

[16] Cohen, Andrew and Michael Mazzeo (2007). Market Structure and Competition Among Retail Depository Institutions. Review of Economics and Statistics, 89: 60-74.

[17] Cutler, David and Jonathan Gruber (1996). Does Public Insurance Crowd Out Private Insurance? Quarterly Journal of Economics, 111(2), pp.391-430

[18] Duggan, Mark (2000). Hospital Ownership and Public Medical Spending. Quarterly Journal of Economics, 115(4): 1343-1373

[19] Duggan, Mark (2002). Hospital Market Structure and the Behavior of Not-For-Profit Hospitals RAND Journal of Economics, 33(3): 433-446.

[20] Gaynor Martin and William Vogt (2003). Competition among hospitals. RAND Journal of Economics, 34(4): 764-785.

[21] Gruber, Jonathan and Daniel Hungerman (2005). Faith-Based Charity and Crowd Out During the Great Depression. Journal of Public Eocnomics, forthcoming.

[22] Harrison, Paige M. \& Allen J. Beck (2005). Prisoners in 2004. US Department of Justice, Bureau of Justice Statistics, NCJ 210677.

[23] Heckman, James J. et al (1998), "Characterizing Selection Bias Using Experimental Data," Econometrica, 66:5, pp. 1017-1098.

[24] Heinrich Carolyn and Elizabeth Fournier (2004). "Dimensions of Publicness and Performance in Substance Abuse Treatment Organizations" Journal of Policy Analysis and Management, $23(1), 49-70$. 
[25] Jia, Panle (2006). What Happens When Walmart Comes to Town: An Empirical Analysis of the Discount retailing Industry. MIT University working paper.

[26] Kingma, Bruce (1989). An Accurate Measurement of the Crowd-Out Effect, Income Effect and Price Effect for Charitable Contributions. Journal of Political Economy, 93: 1197-1207.

[27] Lakdawalla, Darius and Tomas Philipson (2006). The Nonprofit Sector and Industry Performance" Journal of Public Economics, forthcoming.

[28] Lo Sasso, Anthony and Thomas C. Buchmueller (2004). The effect of the state children's health insurance program on health insurance coverage. Journal of Health Economics, 23: 1059-1082.

[29] Mark T.L., Coffey R.M., McKusick D.R., Harwood H., King E., Bouchery E., Genuardi J., Vandivort R., Buck J., Dilonardo J. (2005). National Estimates of Expenditures for Mental Health Services and Substance Abuse Treatment, 1991-2001 SAMHSA Publication No. SMA 05-3999. Rockville, MD: Substance Abuse and Mental Health Services Administration.

[30] Maddala, G.S. Limited Dependent and Qualitative Variables in Econometrics, Cambridge University Press, Cambridge UK, 1983.

[31] Mazzeo, Michael (2002b). Product choice and oligopoly market structure. RAND Journal of Economics, 33(2): 1-22.

[32] Politis, D., J. Romano and M. Wolf (1999). Subsampling. Springer Series in Statistics. Springer: New York.

[33] Rask, Kevin and Kimberly (2000). Public insurance substituting for private insurance: new evidence regarding public hospitals, uncompensated care funds, and medicaid. Journal of Health Economics, 19(1): 1-31.

[34] SAMHSA: Substance Abuse and Mental Health Services Administration (2004). Office of Applied Studies. National Survey of Substance Abuse Treatment Services (N-SSATS): 2003. Data on Substance Abuse Treatment Facilities, DASIS Series: S-24, DHHS Publication No. (SMA) 04-3966, Rockville, MD. 
[35] Shore-Sheppard, Lara, Thomas C. Buchmueller, and Gail A. Jensen (2000). Medicaid and crowding out of private insurance: a re-examination using firm level data. Journal of Health Economics, 19(1): 61-91.

[36] Sindelar, Jody and Todd Olmstead (2005). Does the impact of managed care on substance abuse treatment services vary by profit status? Health Services Research, 40(6p1): 1862-1882.

[37] Tamer, Elie (2003). Incomplete Simultaneous Discrete Response Model with Multiple Equilibria. Review of Economic Studies, 70(1): 147-167

[38] Wheeler and Nahra (2000). Private and Public Ownership in Outpatient Substance Abuse Treatment: Do we have a two-tiered system? Administration and Policy in Mental Health, $27(4)$. 


\section{A Appendix: Computating confidence intervals for the identified set}

Recall that the $95 \%$ confidence interval for the identified set, $\Theta_{95}$, requires finding the set of $\theta$ s for which the value of the objective function is within a specified neighborhood, $c_{95}$, of the minimum. That is,

$$
\Theta_{95}=\theta: Q(\theta)-Q(\widehat{\theta}) \leq c_{95}
$$

Chernozhukov, Hong and Tamer (2007) provide a subsampling algorithm to find the correct c95 for a given sample. We implement the algorithm using the eight steps detailed below.

1. Perturb $\theta$ around $\widehat{\theta}$, compute the objective function and save the values of $Q(\theta)$ and $\theta$. We compute the objective function at 70,000 random perturbations of the parameters around $\widehat{\theta}$.

2. Select $B=100$ subsamples, where each subsample, $b$, is comprised of a quarter of the observed markets. There is not much guidance about how large the subsamples should be (see Politis, Romano and Wolf (1999) for some discussion of this issue). Ciliberto and Tamer (2006), however, report that their intervals are relatively robust to subsample size.

3. For each subsample, compute $\widehat{\theta}_{b}=\arg \min Q^{b}(\theta)$. This is an additional minimization step that is completed once for each subsample. Following from Ciliberto and Tamer, we use $\widehat{\theta}$ as our starting value for each subsample. The minimum is obtained using a Nelder-Mead simplex minimization procedure.

4. Take a starting value of $c_{t}=c_{0}$. As suggested by Ciliberto and Tamer, we select one quarter of the minimized objective function.

5. Find all values of $\theta$ for which the objective function is within $c_{t}$ of the minimum. That is, we find the set $\Theta_{t}$, defined as:

$$
\Theta_{t}=\theta: Q(\theta)-Q(\widehat{\theta}) \leq c_{t}
$$

6. For each subsample, $b$, compute, $a_{b}$, which is the size of the neighborhood around the subsample objective function value generated by the parameter vectors in $\Theta_{t}$.

$$
a_{b}=\sup _{\theta \in \Theta_{t}}\left[Q^{b}(\theta)-Q^{b}\left(\widehat{\theta}_{b}\right)\right]
$$


7. Repeat steps 5 and 6 , replacing $c_{t}$ with the 95 th percentile of $\left\{a_{1}, \ldots, a_{B}\right\}$. Repeat until the $c_{t}$ s from two successive iterations are arbitrarily close to one another. Then set $c_{95}$ equal to the converged $c_{t}$.

8. Use $c_{95}$ to obtain $\Theta_{95}$. 
Table 1

Frequency of markets by outcome

\begin{tabular}{lccc}
\hline $\begin{array}{l}\mathrm{G}=\text { Government Clinics } \\
\mathrm{F}=\text { For-profit Clinics }\end{array}$ & $\begin{array}{c}\text { Zero Non- } \\
\text { Profit }\end{array}$ & $\begin{array}{c}\text { One Non- } \\
\text { Profit }\end{array}$ & $\begin{array}{c}\text { Two Non- } \\
\text { Profits }\end{array}$ \\
\hline $\mathrm{G}=0, \mathrm{~F}=0$ & 0.318 & 0.256 & 0.068 \\
$\mathrm{G}=1, \mathrm{~F}=0$ & 0.134 & 0.038 & 0.022 \\
$\mathrm{G}=0, \mathrm{~F}=1$ & 0.033 & 0.052 & 0.029 \\
$\mathrm{G}=1, \mathrm{~F}=1$ & 0.037 & 0.014 & 0.013 \\
\hline \hline
\end{tabular}

Note: There are 3 types of clinics and 12 possible outcomes. The sum of all cells equals 1.

Table 2

Market characteristics

\begin{tabular}{lccccc}
\hline \hline & All markets & \multicolumn{3}{c}{ Number of clinics } & \\
& & 0 & 1 & $2+$ \\
\hline Population & 23,858 & 14,439 & 21,698 & 37,278 \\
Pct white & 0.846 & 0.832 & 0.841 & 0.868 \\
Pct divorced for females age 25+ & 0.097 & 0.090 & 0.096 & 0.105 \\
Male Median Age & 36.38 & 36.97 & 36.51 & 35.54 \\
For-profit Hospital Share & 0.163 & 0.200 & 0.153 & 0.138 \\
Nurses per 10,000 residents & 0.226 & 0.160 & 0.220 & 0.306 \\
& & & & \\
$N$ & 1702 & 541 & 673 & 488 \\
\hline \hline
\end{tabular}


Table 3

Number of clinics in a market

\begin{tabular}{|c|c|c|c|c|c|c|}
\hline \multirow{2}{*}{$\begin{array}{l}\text { Dependent variable: } \\
\text { Dep. variable values } \\
\text { Model }\end{array}$} & \multicolumn{2}{|c|}{$\begin{array}{c}\text { Government } \\
\{0,1\}\end{array}$} & \multicolumn{2}{|c|}{$\begin{array}{c}\text { Non-profit } \\
\{0,1,2\}\end{array}$} & \multicolumn{2}{|c|}{$\begin{array}{c}\text { For-profit } \\
\{0,1\}\end{array}$} \\
\hline & Probit & $\begin{array}{c}\text { Marginal } \\
\text { effect }\end{array}$ & $\begin{array}{l}\text { Ordered } \\
\text { probit }\end{array}$ & $\begin{array}{c}\text { Marginal } \\
\text { effect }\end{array}$ & Probit & $\begin{array}{c}\text { Marginal } \\
\text { effect }\end{array}$ \\
\hline \multicolumn{7}{|l|}{ Market structure indicators } \\
\hline Government & -- & -- & $\begin{array}{l}-0.768 \\
(-9.73)\end{array}$ & -0.361 & $\begin{array}{l}-0.032 \\
(-0.32)\end{array}$ & -0.007 \\
\hline First Non-profit & $\begin{array}{l}-0.939 \\
(-10.05)\end{array}$ & -0.252 & -- & -- & $\begin{array}{l}-0.062 \\
(-0.65)\end{array}$ & -0.013 \\
\hline Second Non-Profit & $\begin{array}{l}-0.035 \\
(-0.28)\end{array}$ & -0.009 & -- & -- & $\begin{array}{l}0.016 \\
(0.14)\end{array}$ & 0.003 \\
\hline For-profit & $\begin{array}{l}-0.573 \\
(-0.57)\end{array}$ & -0.015 & $\begin{array}{l}-0.017 \\
(-0.20)\end{array}$ & -0.021 & -- & -- \\
\hline \multicolumn{7}{|l|}{ Demographic characteristics } \\
\hline Log(population) & $\begin{array}{c}0.739 \\
(10.05)\end{array}$ & 0.201 & $\begin{array}{c}0.693 \\
(13.54)\end{array}$ & 0.254 & $\begin{array}{l}0.506 \\
(7.26)\end{array}$ & 0.104 \\
\hline Percent white & $\begin{array}{l}-0.022 \\
(-9.00)\end{array}$ & -0.006 & $\begin{array}{l}0.011 \\
(5.06)\end{array}$ & 0.005 & $\begin{array}{l}0.013 \\
(3.90)\end{array}$ & 0.003 \\
\hline Percent females divorced & $\begin{array}{l}0.069 \\
(3.34)\end{array}$ & 0.019 & $\begin{array}{l}0.136 \\
(8.51)\end{array}$ & 0.056 & $\begin{array}{l}0.112 \\
(5.14)\end{array}$ & 0.023 \\
\hline Male Median Age & $\begin{array}{l}-0.012 \\
(-1.04)\end{array}$ & -0.003 & $\begin{array}{l}-0.050 \\
(-5.32)\end{array}$ & -0.021 & $\begin{array}{l}-0.051 \\
(-4.15)\end{array}$ & -0.011 \\
\hline For-profit Hospital Share & $\begin{array}{l}-3.145 \\
(-8.35)\end{array}$ & -0.856 & $\begin{array}{l}-2.024 \\
(-7.04)\end{array}$ & -0.892 & $\begin{array}{l}-1.932 \\
(-4.79)\end{array}$ & -0.399 \\
\hline Nurses per 100 residents & $\begin{array}{l}0.783 \\
(4.71)\end{array}$ & 0.213 & $\begin{array}{l}0.577 \\
(3.98)\end{array}$ & 0.287 & $\begin{array}{l}0.445 \\
(2.45)\end{array}$ & 0.092 \\
\hline
\end{tabular}

Note: $N=1,702$ for all models. t-statistics are in parentheses. Each model contains a constant. 
Table 4

Parameter estimates

\begin{tabular}{lccc}
\hline \hline Type of clinic: & Government & Non-profit & For-profit \\
\hline Competitive effects & & & \\
Government & & $-2.163,-0.736]$ & {$[-2.462,-0.875]$} \\
First non-profit & - & -1.005 & -1.461 \\
& {$[-2.645,-1.335]$} & {$[-2.107,-1.738]$} & {$[-1.386,-0.281]$} \\
Second non-profit & -2.082 & -1.960 & -0.976 \\
& {$[-1.210,-0.0001]$} & - & {$[-1.384,-0.032]$} \\
For-profit & -0.069 & -0.790 \\
& {$[-2.014,-0.237]$} & {$[-1.182,-0.477]$} & - \\
Demographic characteristics & -0.983 & -0.817 & \\
Log(population) & & & \\
Percent white & {$[0.831,1.334]$} & {$[0.650,0.914]$} & {$[0.741,1.689]$} \\
Percent females & 1.058 & 0.784 & 1.207 \\
divorced & {$[-0.033,-0.025]$} & {$[0.010,0.025]$} & {$[0.011,0.025]$} \\
Male Median Age & -0.026 & 0.022 & 0.020 \\
State Share of For-Profit & {$[-6.927,-5.228]$} & {$[-4.912,-3.402]$} & {$[-5.314,-1.196]$} \\
Hospitals & -6.145 & -3.747 & -3.362 \\
Nurses per 10,000 & {$[0.750,1.562]$} & {$[0.623,1.185]$} & {$[0.481,1.640]$} \\
& 1.073 & 0.976 & 1.149 \\
\hline \hline
\end{tabular}

Note: The numbers in brackets are the lower and upper limits of the $95 \%$ confidence interval. The number below the confidence interval is the "point estimate." 
Table 5

Probabilities of multiple equilibria

\begin{tabular}{lccc}
\hline \hline $\mathrm{G}=$ Government Clinics & Zero Non-Profit & One Non-Profit & Two Non-Profits \\
$\mathrm{F}=$ For-profit Clinics & & {$[0.168,0.356]$} & {$[0.021,0.216]$} \\
$\mathrm{G}=0, \mathrm{~F}=0$ & 0.000 & 0.219 & 0.141 \\
& & {$[0.190,0.709]$} & {$[0.168,0.313]$} \\
$\mathrm{G}=1, \mathrm{~F}=0$ & $0.351,0.557]$ & 0.315 & 0.221 \\
& 0.460 & {$[0.213, .479]$} & {$[0.035,0.146]$} \\
$\mathrm{G}=0, \mathrm{~F}=1$ & {$[0.260,0.555]$} & .336 & 0.084 \\
$\mathrm{G}=1, \mathrm{~F}=1$ & 0.431 & $0.019,0.694]$ & 0.000 \\
& {$[0.399,0.696]$} & 0.228 & \\
\hline \hline
\end{tabular}

Note: The numbers in brackets are the $95 \%$ confidence interval, based on the parameter set $\Theta_{95}$. The bottom number in each cell is calculated using the "point estimates" of the model.

Table 6

Conditions for multiple equilibria with different numbers of clinics

\begin{tabular}{c|cr|cc}
\hline \hline $\begin{array}{c}\text { Observed } \\
\text { outcome }\end{array}$ & \multicolumn{2}{c}{ Alternative outcome \#1 } & \multicolumn{2}{c}{ Alternative outcome \#2 } \\
Configuration & $\begin{array}{c}\text { Necessary } \\
\text { conditions }\end{array}$ & Configuration & $\begin{array}{c}\text { Necessary } \\
\text { conditions }\end{array}$ \\
\hline $\mathbf{( 1 , 0 , 0 )}$ & $\mathbf{( 0 , 1 , 1 )}$ & $\delta_{N G}<\delta_{N F}, \delta_{F G}<\delta_{F N}$ & $\mathbf{( 0 , 2 , 0 )}$ & $\delta_{N G}<\gamma_{N N}$ \\
$(\mathbf{1}, \mathbf{1}, \mathbf{0})$ & $\mathbf{( 0 , 2 , 1 )}$ & $\delta_{N G}<\delta_{N F}, \delta_{F G}<\gamma_{F N}$ & - & \\
$(1,0,1)$ & $(0,2,1)$ & $\delta_{N G}<\gamma_{N N}$ & - & \\
$(\mathbf{0 , 1}, \mathbf{0})$ & $\mathbf{( 1 , 0 , 1 )}$ & $\delta_{G N}<\delta_{G F}, \delta_{F G}<\delta_{F N}$ & - & $\delta_{N F}<\gamma_{N N}$ \\
$(0,2,0)$ & $(1,1,1)$ & $\gamma_{G N}<\delta_{G F}, \gamma_{F N}<\delta_{F G}$ & - & \\
$(0,0,1)$ & $(1,1,0)$ & $\delta_{G F}<\delta_{G N}, \delta_{N F}<\delta_{N G}$ & $(0,2,0)$ & \\
$(0,1,1)$ & $(1,2,0)$ & $\delta_{G F}<\gamma_{G N}, \delta_{N F}<\delta_{N G}$ & - & \\
\hline \hline
\end{tabular}


Table 7

Comparison of data and predicted outcomes

\begin{tabular}{lcc}
\hline \hline & $\begin{array}{c}\text { Number of markets with type } t \text { clinic } \\
\text { Data }\end{array}$ & Estimates \\
\hline Government & 415 & {$[369.9,414.4]$} \\
& & 385.2 \\
Non-profit & 836 & {$[811.6,850.5]$} \\
& & 839.2 \\
For-profit & 281 & {$[288.8,325.9]$} \\
& & 307.5 \\
Clinic of any type & 1161 & {$[1161.0,1161.0]$} \\
& & 1161.0 \\
\hline \hline
\end{tabular}

Note: See the note for Table 5.

Table 8

Simulated counterfactual experiment: Close all public clinics $(G)$

\begin{tabular}{|c|c|c|c|c|c|c|}
\hline & \multicolumn{6}{|c|}{ Number of Markets with Type $t$ Clinic } \\
\hline & \multicolumn{2}{|c|}{ All Markets } & \multicolumn{2}{|c|}{$\%$ White $<$ Median } & \multicolumn{2}{|c|}{$\%$ White $\geq$ Median } \\
\hline & Data & Counterfactual & Data & Counterfactual & Data & Counterfactual \\
\hline Government & 415 & 0 & 279 & 0 & 136 & 0 \\
\hline Non-profit & 836 & $\begin{array}{c}{[887.4,979.9]} \\
921.5\end{array}$ & 356 & $\begin{array}{c}{[394.4,446.6]} \\
414.3\end{array}$ & 480 & $\begin{array}{c}{[492.0,534.8]} \\
507.1\end{array}$ \\
\hline For-profit & 281 & $\begin{array}{c}{[332.7,411.0]} \\
377.3\end{array}$ & 132 & $\begin{array}{c}{[162.2,207.2]} \\
189.3\end{array}$ & 149 & $\begin{array}{c}{[168.8,202.6]} \\
188.0\end{array}$ \\
\hline Any clinic & 1161 & $\begin{array}{c}{[1048.7,1076.7]} \\
1061.8\end{array}$ & 560 & $\begin{array}{c}{[476.4,495.0]} \\
485.3\end{array}$ & 601 & $\begin{array}{c}{[572.0,581.9]} \\
576.4\end{array}$ \\
\hline
\end{tabular}

Note: See the note for Table 5. 
Table 9

Counterfactual Results

\begin{tabular}{|c|c|c|c|c|c|c|c|}
\hline \multicolumn{8}{|c|}{ Experiment: Close a public clinic } \\
\hline \multicolumn{3}{|c|}{$\begin{array}{c}\text { Original } \\
\text { Configuration }\end{array}$} & \multicolumn{5}{|c|}{ Probability of no replacement entry } \\
\hline G & $\mathrm{N}$ & $\mathrm{F}$ & Mean & Std Dev & Min & $\operatorname{Max}$ & $\begin{array}{c}\text { Number of } \\
\text { Markets }\end{array}$ \\
\hline 1 & 0 & 0 & 0.451 & 0.245 & 0 & 0.96 & 228 \\
\hline 1 & 0 & 1 & 0.586 & 0.163 & 0.26 & 0.92 & 41 \\
\hline 1 & 1 & 0 & 0.506 & 0.216 & 0.04 & 0.86 & 64 \\
\hline 1 & 1 & 1 & 0.684 & 0.096 & 0.52 & 0.86 & 23 \\
\hline 1 & 2 & 0 & 0.707 & 0.201 & 0.34 & 1 & 37 \\
\hline \multicolumn{8}{|c|}{ Experiment: Close a non-profit clinic } \\
\hline \multicolumn{3}{|c|}{$\begin{array}{c}\text { Original } \\
\text { Configuration } \\
\end{array}$} & \multicolumn{5}{|c|}{ Probability of no replacement entry } \\
\hline G & $\mathrm{N}$ & $\mathrm{F}$ & Mean & Std Dev & Min & Max & $\begin{array}{l}\text { Number of } \\
\text { Markets }\end{array}$ \\
\hline 0 & 1 & 0 & 0.511 & 0.235 & 0.015 & 0.995 & 435 \\
\hline 0 & 1 & 1 & 0.739 & 0.188 & 0.275 & 0.985 & 89 \\
\hline 0 & 2 & 0 & 0.725 & 0.200 & 0.235 & 0.995 & 116 \\
\hline 0 & 2 & 1 & 0.992 & 0.010 & 0.965 & 1 & 50 \\
\hline 1 & 1 & 0 & 0.823 & 0.172 & 0.34 & 1 & 64 \\
\hline 1 & 2 & 0 & 0.935 & 0.060 & 0.78 & 1 & 37 \\
\hline
\end{tabular}


Table 10:

Marginal entry probabilities into "marginal" markets

\begin{tabular}{lcccc}
\hline \hline & Type $G$ entry & Type $N$ entry & Type $F$ entry & No Entry \\
$\begin{array}{l}\text { Probability at mean of } \\
\text { explanatory variables }\end{array}$ & $7.99 \%$ & $24.30 \%$ & $2.39 \%$ & $65.32 \%$ \\
\hline $\begin{array}{l}\text { Effect of } 1 \% \text { increase in } \\
\text { percentage white }\end{array}$ & $-.43 \%$ & $+.67 \%$ & $+.07 \%$ & $-.32 \%$ \\
$\begin{array}{l}\text { Effect of } \$ 1,000 \text { increase in } \\
\text { median household income }\end{array}$ & $(-9.36)$ & $(6.46)$ & $(1.87)$ & $(-2.99)$ \\
\hline \hline
\end{tabular}

Note: Across the 892 marginal markets, the average of percentage white is $82.8 \%$ and the average of the median household income is $\$ 33,017$. $t$-statistics for the marginal probabilities are given in parentheses. 